\title{
STUDY ON SECURITY AND QUALITY OF SERVICE IMPLEMENTATIONS IN P2P OVERLAY NETWORK FOR EFFICIENT CONTENT DISTRIBUTION
}

\author{
K.Ramalakshmi ${ }^{1}$, P.K.Sasikumar ${ }^{2}$ \\ ${ }^{1}$ P.G Scholar Computer Science Eng, Dept. of CSE, Tamilnadu College of Engineering, Coimbatore, India \\ ${ }^{2}$ Assistant Professor, Dept. of CSE, Tamilnadu College of Engineering, Coimbatore, India
}

\begin{abstract}
Peer-to-peer $(P 2 P)$ is a distributed system without any centralized control or hierarchical organization nodes organize itself in a dynamic way. It allows different applications to achieve efficient and simple file sharing. Without any authentication adversary nodes can spoof the identity and spoil the integrity by falsifying the messages in the overlay. This enables malicious nodes to launch man-inthe-middle or denial-of-service attacks and many security related attacks. P2P systems require a sufficient amount of trust from their nodes which are all participates in the network for AAA (Authentication, Authorization and Availability). From the analysis it aims to provide the prediction of optimized path in the network for efficient file sharing and the identification of necessary security methods in the network to provide security to decentralized $22 p$ network.
\end{abstract}

Keywords: Decentralized, fault tolerance, access latency, double layer security, swarm intelligence, self organized, trust management, threshold value, secured network, integrity, authentication, authorization.

\section{INTRODUCTION}

Overlay network is a computer network which can be built on top of another underlying network with the purpose to implement the services which is not available in the existing network. The main goal of the overlay network is to interconnect several LANs together. Because of the nodes of P2P run on top of the internet it must be an overlay network. $\mathrm{P} 2 \mathrm{P}$ is a distributed system without any hierarchical organization or centralized control nodes can communicate with each other and organize itself in a dynamic way. Each node may act as a client or server or router. A P2P network provides self organized and fault tolerant mechanisms to locate nodes anywhere on a network without maintaining a large amount of routing state even in large node densities. Peers in the network form a self-organized distributed overlay networks that are overlayed with the Internet Protocol (IP) networks which is built on the underlying physical network to provide the services which is not available in the existing network and has the features such as robust wide-area routing architecture, efficient data items search, nearby peers selection, redundant storage, permanence, hierarchical naming, trust and authentication, anonymity, massive scalability, fault tolerance and supports efficient resource sharing.
P2P overlay network can be viewed as a model of spanning a large spectrum of the communication nodes framework, which specifies a cooperative, multiple, autonomous, component databases, fully-distributed network design. It is built at the application layer and use the underlying network for the exchange of messages. A node (peer) may act as a client or a server or router whenever an object is requested or served or forwarded. P2P networks feature an enhancement of the use of information, bandwidth and computing resources. Structured P2P networks implements DHT (Distributed Hash Tables) which uses the consistent hashing to assign each file to a particular peer as ownership to that file that enables search for a resource on the network by using the hash tables. Unstructured P2P networks will not impose a particular topology on the overlay network by design but rather the nodes form the random connections to each other. Unstructured P2P networks are highly robust in the presence of high rates of churn i.e., when large number of peers are suddenly joining and leaving the network. Replicated content distribution of P2P network enables the demanded contents to be get closer to the clients by geographically multiplying the source of information which in turn reduce both the access latency and network traffic. QoS is a method to assure a bandwidth relationship between individual applications or protocols. It minimizes the cost, access latency and increase the availability by using the replication technique. 


\section{SWARM INTELLIGENCE}

Swarm Intelligence (SI) depends on the collective behavior of decentralized, self-organized systems which may be natural or artificial. This system is developed in the work on artificial intelligence. SI systems consist of a distributed population of some simple agents as solutions can interact with one another locally and also with their environment. The inspiration often comes from nature, especially biological systems. Those agents will follow some very simple rules without any centralized control structure dictating how individual agents should behave local and to a certain degree random interactions between such agents lead to the upcoming usage of "intelligent" global behavior which may be not known by the individual agents. Examples of SI in nature may include bee colonies, ant colonies, fish schooling, bird flocking, animal herding and bacterial growth and used in robots is called swarm robotics, while 'swarm intelligence' refers to the more general set of algorithms. 'Swarm prediction' will be used in the forecasting problems. The swarm intelligence is implemented and the network security has been improved and the functions of the swarm intelligence works based on the degree of replication. The degree of replication defines the percentage of participating nodes having the same files over the network Bio-inspired algorithms are increasingly attracting attention in solving optimization problems. In an overview of biological facts about social insects, their inspired algorithms and application areas in computer engineering and science are presented. Among all social insects, the foraging behavior of ant and bee colonies, and how it can be used to solve search problems, is particularly popular.

\subsection{Artificial Bee Colony Algorithm}

Artificial bee colony algorithm (ABC) is a meta-heuristic algorithm which simulates the collective behavior of honey bees. The ABC algorithm has three types of bee phases called scout bee, employed bee and onlooker bee. The employed bee phase uses the deterministic selection and the onlooker bee phase uses the probabilistic selection to finds the sources in the neighborhood of the solutions by local searches. In the scout bee phase efficient food sources will be identified by the flooding of request in the searching process for solutions and new solutions are inserted instead of them to explore new regions in the search space. The algorithm has a well-balanced exploration and exploitation ability.

\subsection{Comparison with other Search Methods}

Swarm Intelligence based optimization algorithms mimic the nature to drive a search towards the optimal solution. A key difference between SI and direct search algorithms such as random walk and hill climbing is that instead of a single solution SIOAs use a population of solution for every iteration. As a population of solution is processed in an iteration the population of solutions will be the outcome of each iteration. SIOA population can be used to converge to the optimum solution if an optimization problem has a single optimum. However if an optimization problem has multiple optimal solutions an SIOA can be used to capture them in its final population. SIOAs include the Ant Colony Optimization (ACO) algorithm, the Genetic Algorithm (GA) and the Particle Swarm Optimization (PSO) algorithm. Common to all population-based search methods SIOA generates variations of the solution being sought. Some search methods like greedy criterion can be used for the decision on which generated solution to retain. Such a criterion can accept the new solution if it increases the value of the optimized result. Swarm intelligence has also been applied for data mining.

Swarm based P2P model uses Alliance theory for peering where high contributing nodes (Power Nodes) have high ranking based on their share ratios and nodes may be served by the direct server and in small world networks every node can also be connected to every other node in the swarm by the small number of path length. Alliance members have common trust and treaty as a node receives new content it forwards among its alliance members. First alliance members are mutually trusted and all members of an alliance have an active connection with other members and also applying security policies in alliance is much easier. 


\section{RESEARCH ISSUES IN QUALITY OF SERVICE AWARE CONTENT DISTRIBUTION AND DIFFERENT KINDS OF SECURITY IMPLEMENTATION IN P2P NETWORK}

Table-3.1 : Quality of service aware content distribution and different kinds of security implementation in p2p network

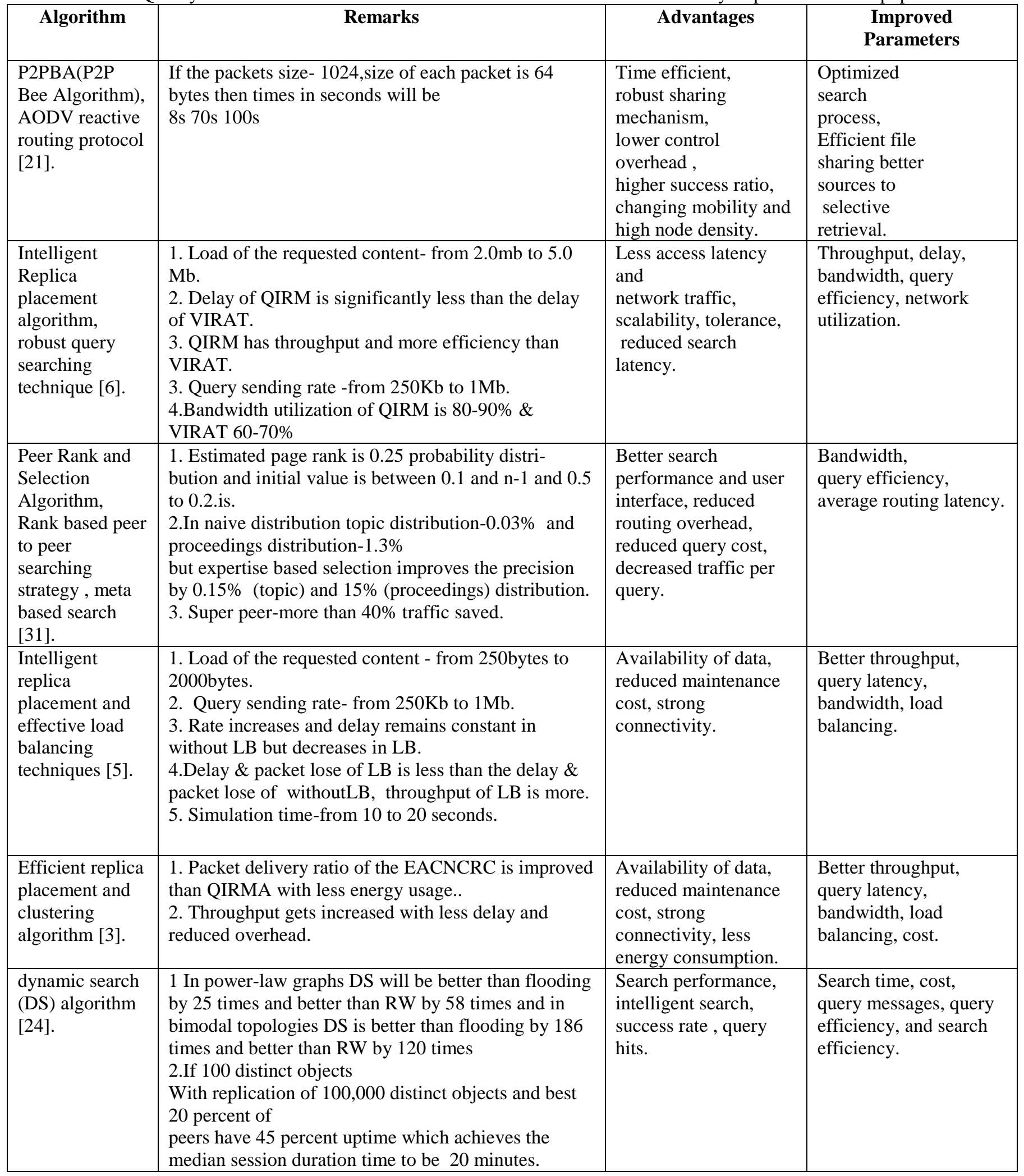




\begin{tabular}{|c|c|c|c|}
\hline & $\begin{array}{l}\text { 3.Dynamic querying model has Poisson } \\
\text { distribution with the idle time as } 50 \text { minutes } \\
\text { 4. MBFS with APS learning, the transmission } \\
\text { probability p is set as } 0.2 \text {. } \\
\text { 5. SE of DS is } 24 \text { percent better than that of RW, and } \\
31 \text { times better than that of MBFS. }\end{array}$ & & \\
\hline $\begin{array}{l}\text { Dynamic } \\
\text { Adaptation of } \\
\text { Connection } \\
\text { algorithm } \\
\text { dynamic } \\
\text { distributed hash } \\
\text { table (DDHT), } \\
\text { round-trip time } \\
\text { (RTT)[2]. }\end{array}$ & $\begin{array}{l}\text { 1.DDHTs- dynamic updates, scalable, fault-tolerant, } \\
\text { administration-free and efficiently handle large } \\
\text { volume of data items } \\
\text { 2. RTT-very fast, high qualities dynamic tree } \\
\text { adaptation (minimizes the service disruption). } \\
\text { 3. It speeds up the connection and re- connection . }\end{array}$ & $\begin{array}{l}\text { Fault-tolerant, adminis } \\
\text {-tration free, } \\
\text { minimizes any service } \\
\text { disruption }\end{array}$ & $\begin{array}{l}\text { Fast access, quality } \\
\text { tree, adaptation. }\end{array}$ \\
\hline $\begin{array}{l}\text { Adaptive search } \\
\text { algorithm } \\
\text { Process } \\
\text { Query Receive } \\
\text { Query Hit [12]. }\end{array}$ & $\begin{array}{l}\text { 1. Proposed method decreases the response time } \\
\text { where minimum bandwidth and maximum latency as } \\
2 \mathrm{Mbps} \text { and } 20 \text { msecs. respectively. } \\
\text { 2. Reduced cost for a node is } 6.25 \text {. } \\
\text { 3. A weigh of } 65 \% \text { to the transfer speed and } 20 \% \text { to } \\
\text { latency and the remaining } 15 \% \text { to the past response } \\
\text { (popularity of the peer) is given. } \\
\text { 4. If } 1000 \text { nodes and } 50 \text { different objects then degree } \\
\text { of node varies from } 3 \text { to } 12 \text { with TTL limit is from } 1 \\
\text { to } 5 \text {. }\end{array}$ & $\begin{array}{l}\text { Improves the } \\
\text { scalability, improved } \\
\text { performance, } \\
\text { Minimized message } \\
\text { overhead. }\end{array}$ & $\begin{array}{l}\text { Latency, bandwidth, } \\
\text { low latency and less } \\
\text { congestion. }\end{array}$ \\
\hline $\begin{array}{l}\text { First-In-First- } \\
\text { Out algorithm } \\
\text { Tree based } \\
\text { Interactive } \\
\text { MultimEdia } \\
\text { System } \\
\text { (TIMES)[33]. }\end{array}$ & $\begin{array}{l}\text { 1.It satisfies the large number of non- synchronization } \\
\text { Requests. } \\
\text { 2. Achieves the interactive services. } \\
\text { 3.Peer will cache the first initial } 3 \text { minutes of video } \\
\text { and will never replaces this part until it depart }\end{array}$ & $\begin{array}{l}\text { Interactive operations, } \\
\text { less interruption, } \\
\text { limited buffer space. }\end{array}$ & $\begin{array}{l}\text { Reduce the server } \\
\text { loading, flexibility, } \\
\text { Bandwidth. }\end{array}$ \\
\hline $\begin{array}{l}\text { ROMEO(Remot } \\
\text { e Collaborative } \\
\text { Real-Time } \\
\text { Multimedia } \\
\text { Experience over } \\
\text { the Future } \\
\text { Internet) } \\
\text { resource over- } \\
\text { reservation } \\
\text { techniques [10]. }\end{array}$ & $\begin{array}{l}\text { 1. DVB-T2 -3D media's live simultaneous delivery. } \\
\text { 2. Super-peer- improves scalability. } \\
\text { 3. Enhances the service provisioning and has real-time } \\
\text { control over the flow prioritization. } \\
\text { 4. Packet delay and jitter control is achieved by traffic } \\
\text { load balancing and control of unnecessary congestion } \\
\text { occurrence. }\end{array}$ & $\begin{array}{l}\text { Low bandwidth, small } \\
\text { delay, low jitter, less } \\
\text { loss, reduction of } \\
\text { signalling overhead } \\
\text { increased resource } \\
\text { utilization, flexible } \\
\text { and cost-effective } \\
\text { control mechanisms. }\end{array}$ & $\begin{array}{l}\text { High quality real-time } \\
\text { collaboration, multiple } \\
\text { enhancement layers of } \\
\text { views without high } \\
\text { complexity and } \\
\text { buffering requirement, } \\
\text { network utilization. }\end{array}$ \\
\hline $\begin{array}{l}\text { Data pipelines, } \\
\text { asymmetric } \\
\text { approach[15]. }\end{array}$ & $\begin{array}{l}\text { 1.Asymmetric approach- } \\
\text { reduces the data access latency by } 20-23 \% \text { while } \\
\text { symmetric approach has } 12-18 \% \text { of access latency. } \\
2 \text {. Transmission rate is increased as } 5 \mathrm{Mbps} \& \text { has no } \\
\text { network congestion. } \\
\text { 3. } 30-50 \% \text { less data traffic than the Simple Cache } \\
\text { Approach is achieved by cooperative cache schemes } \\
\text { (ICC, SCC, ACC). }\end{array}$ & $\begin{array}{l}\text { Removal of processing } \\
\text { overhead and reduced } \\
\text { data processing delay. }\end{array}$ & $\begin{array}{l}\text { End-to-end interaction, } \\
\text { traffic control. }\end{array}$ \\
\hline $\begin{array}{l}\text { Optimized Bio- } \\
\text { inspired } \\
\text { Algorithm } \\
\text { (OBAME). } \\
\text { ant colony- } \\
\text { inspired }\end{array}$ & $\begin{array}{l}\text { Among } 20 \text { nodes } 200,400,600,800,1000 \text { queries can } \\
\text { be answered by OBAME within the particular } \\
\text { response time which outperforms the AVAs and } \\
\text { BCAs by reduced response time with reduced network } \\
\text { traffic. }\end{array}$ & $\begin{array}{l}\text { Maximized search } \\
\text { efficiency in P2P } \\
\text { databases, solving } \\
\text { optimization } \\
\text { problems, eliminate } \\
\text { flooding. }\end{array}$ & $\begin{array}{l}\text { Network traffic, query } \\
\text { response time. } \\
\text { availability, efficiency, } \\
\text { accuracy. }\end{array}$ \\
\hline
\end{tabular}




\begin{tabular}{|c|c|c|c|}
\hline $\begin{array}{l}\text { algorithms } \\
\text { (ACAs) and bee } \\
\text { colony- inspired } \\
\text { algorithms } \\
\text { (BCAs)[13] }\end{array}$ & & & \\
\hline $\begin{array}{l}\text { Bio-inspired } \\
\text { resource } \\
\text { discovery } \\
\text { scheme, Q- } \\
\text { learning and } \\
\text { erasure } \\
\text { codes(Reed- } \\
\text { Solomon) } \\
\text { random } \\
\text { algorithm, a } \\
\text { group partition } \\
\text { algorithm } \\
\text { highest } \\
\text { available first } \\
\text { (HAF) } \\
\text { algorithm[20]. }\end{array}$ & $\begin{array}{l}\text { 1.If } 10000 \text { nodes, average degree of a nodes in the } \\
\text { network is } 3.5 \text {, } \\
1000 \text { objects distributed } \\
100 \text { queries then one query is propagated every } 20 \\
\text { seconds on average. flood of query message } \\
\text {-production is regulated. } 80 \% \text { of the nodes are up and } \\
50 \% \text { of 'Down' nodes } \\
\text { 2. Hit rate threshold } \delta-0.3 \text { thrld } H \text { is } 0.6 \text {. } \\
\text { 3. Availability threshold- } 0.4 \text {. The maximum number } \\
\text { of blocks k for an object - } 12 \text {. TTL value is } 6 \\
\text { available storage } \geq 30 \%\end{array}$ & $\begin{array}{l}\text { 1.Efficient resource } \\
\text { discovery and } \\
\text { availability of desired } \\
\text { objects } \\
\text { 2.Erasure codes } \\
\text { replication with less } \\
\text { number of available } \\
\text { blocks to construct } \\
\text { original files with } \\
\text { coded fragments saves } \\
\text { storage space and } \\
\text { bandwidth. 3.Power } \\
\text { peer table-maintains } \\
\text { data about number of } \\
\text { hits in } \\
\text { the node to enhance } \\
\text { the availability of } \\
\text { popular objects. }\end{array}$ & $\begin{array}{l}\text { Query success rate and } \\
\text { availability and reduces } \\
\text { the network traffic. }\end{array}$ \\
\hline $\begin{array}{l}\text { Probabilistic } \\
\text { Modelling, } \\
\text { structure } \\
\text { learning and } \\
\text { parameter } \\
\text { learning [4]. }\end{array}$ & $\begin{array}{l}\text { 1. Filtering with routing updating table searching } \\
\text { performance gets improved as } 90 \% \text {. } \\
\text { 2. Global optimum is achieved by efficient training } \\
\text { and decoding based on dynamic programming and } \\
\text { parameter estimation. } \\
3.1 \text { million nodes with a query rate of } 1000 \text { queries } \\
\text { per second, then network traffic will be less than that } \\
\text { of } 0.07 \% \text {. } \\
\text { 4. Communication costs is between } 0.03 \% \text { and } 0.07 \% \\
\text { with reduced communication bandwidth as } 50 \%\end{array}$ & $\begin{array}{l}\text { Save peers from their } \\
\text { blindness, } \\
\text { fast resource } \\
\text { discovery, cost- } \\
\text { effective, accuracy of } \\
90 \% \text {,reduced loss. }\end{array}$ & $\begin{array}{l}\text { Reliability, } \\
\text { bandwidth, } \\
\text { availability, } \\
\text { throughput, } \\
\text { query latency }\end{array}$ \\
\hline $\begin{array}{l}\text { DABC } \\
\text { (Differential } \\
\text { Artificial Bee } \\
\text { Colony), } \\
\text { stochastic } \\
\text { algorithms[23]. }\end{array}$ & $\begin{array}{l}\text { 1.For } 10 \mathrm{D} \text { problem- solution is } 6.78 \mathrm{e}-20(\mathrm{f} 5) \\
\text { 2.For 30D problem- solution is } 4.12 \mathrm{e}-18(\mathrm{f} 5) \\
\text { 3.For 50D problems- solution is } 4.34 \mathrm{e}-17(\mathrm{f} 5) \\
\text { 4.While compare to other solution proposed solution } \\
\text { achieves } 9.26 \mathrm{e}-18(\mathrm{f} 5)\end{array}$ & $\begin{array}{l}\text { Convergence, quality } \\
\text { of solution, } \\
\text { robustness, better } \\
\text { search strategy. }\end{array}$ & $\begin{array}{l}\text { Solutions to dynamic } \\
\text { optimization problems, } \\
\text { suitability, convergence } \\
\text { rate. }\end{array}$ \\
\hline $\begin{array}{l}\text { 1.Automated } \\
\text { Red Teaming } \\
\text { (ART)with } \\
\text { multi-objective } \\
\text { evolutionary } \\
\text { algorithms such } \\
\text { as SPEAII and } \\
\text { NSGAII } \\
2 . \text { Multi- } \\
\text { objective bee } \\
\text { colony } \\
\text { optimization } \\
\text { (MOBCO) } \\
\text { algorithm with } \\
\text { non-dominated } \\
\text { selection and } \\
\text { crowding }\end{array}$ & $\begin{array}{l}1.70 \% \text { of the bees- follow a dance selected from the } \\
\text { top } 50 \% \text { (in terms of crowding distance) of the bees in } \\
B \text { waggle } \\
2.20 \% \text { of the bees follow the next } 30 \% \text { of the dance } \\
\text { in } B \text { waggle, } \\
3 . \text { Last } 10 \% \text { of the bees follow the balance } 20 \% \text { of the } \\
\text { dance in } B \text { waggle. } \\
\text { 4. MOBCO is able to achieve a good convergence } \\
\text { compared to NSGAII. Crossover rate and mutation } \\
\text { rate is N/A }\end{array}$ & $\begin{array}{l}\text { Robustness ART } \\
\text { controller-efficient } \\
\text { communication } \\
\text { proper loading and } \\
\text { execution between } \\
\text { different modules. }\end{array}$ & $\begin{array}{l}\text { End to end } \\
\text { communication and } \\
\text { execution, improved } \\
\text { performance. }\end{array}$ \\
\hline
\end{tabular}




\begin{tabular}{|c|c|c|c|}
\hline $\begin{array}{l}\text { distance ranking } \\
\text { approach [17]. }\end{array}$ & & & \\
\hline $\begin{array}{l}\text { Artificial bee } \\
\text { colony } \\
\text { algorithm } \\
\text { (ABC)[18]. }\end{array}$ & $\begin{array}{l}\text { 1.In } 14 \text { bus system total active and reactive power } \\
\text { loads on the system are } 28.7 \mathrm{MW} \text { and } 16.3 \mathrm{MV} \mathrm{Ar} \\
\text { with voltage as } 1.0 \text { p.u. then the initial power loss } \\
\text { will be } 511.4 \mathrm{~kW} \text { the power loss after reconfiguring as } \\
464.6 \mathrm{~kW} \text {. } \\
\text { 2. Energy saving and cpu time as } 8.15 \text { and } 4.9 \\
\text { 3.For } 33 \text { bus system total load conditions are } \\
5058.25 \mathrm{~kW} \text { and } 2547.32 \mathrm{kvar} \text { with initial losses are } \\
202.68 \mathrm{~kW} \text {. }\end{array}$ & $\begin{array}{l}\text { Minimized power loss, } \\
\text { high node density. }\end{array}$ & $\begin{array}{l}\text { Load balancing, voltage } \\
\text { profile improvement, } \\
\text { better sources to } \\
\text { selective retrieval. }\end{array}$ \\
\hline $\begin{array}{l}\text { Fast mutation } \\
\text { artificial bee } \\
\text { colony } \\
\text { algorithm } \\
\text { or FMABC[29]. }\end{array}$ & $\begin{array}{l}1.50 \% \text { employed bees and } 50 \% \text { onlooker bees } \\
(\mathrm{SN}=15) \text {, limit=100. } \\
\text { 2. Function optimum than ABC. } \\
\text { 3.Mean best and std dev (f7)for ABC is } 0.11550 .1201 \\
\text { and FMABC is } 8.8818 \mathrm{e}-16,0 \text { respectively dimension } \\
10 \text { in dimension } 30 \text { mean best and std dev (f7)for } \\
\text { ABC is } 1.68321 .8912 \text { and FMABC is } 8.8818 \mathrm{e}-160\end{array}$ & $\begin{array}{l}\text { Avoiding the falling } \\
\text { into local optimal, } \\
\text { high node density. }\end{array}$ & $\begin{array}{l}\text { Higher stability of } \\
\text { solutions, load } \\
\text { balancing, improved } \\
\text { convergence rate, } \\
\text { Performance. }\end{array}$ \\
\hline $\begin{array}{l}\text { Multi-Objective } \\
\text { Artificial Bee } \\
\text { Colony } \\
\text { (MOABC) } \\
\text { algorithm with } \\
\text { Pareto concept } \\
\text { and external } \\
\text { archive strategy } \\
\text { [28]. }\end{array}$ & $\begin{array}{l}\text { 1. MOABC algorithm is better than MOCLPSO and } \\
\text { NSGA-II optimization algorithms. } \\
\text { 2. In convergence metric MOABC, MOCLPSO and } \\
\text { NSGA 's Median } 2.8035 \mathrm{e}-005,8.1531 \mathrm{e}-003 \text {, } \\
3.9688 \mathrm{e}+000 \text { and Std } 8.9540 \mathrm{e}-003,1.9448 \mathrm{e}-002 \text {, } \\
1.4822 \mathrm{e}+000 \text { will be respectively. In diversity metric } \\
\text { MOABC, } \\
\text { MOCLPSO and NSGA 's Median } 4.7318 \mathrm{e}-001 \text {, } \\
\text { 7.5949e-001, } 1.1187 \mathrm{e}+000 \text { and Std } 2.7989 \mathrm{e}-001 \text {, } \\
\text { 4.2953e-001, } 8.8914 \mathrm{e}-002 \text { will be respectively. }\end{array}$ & $\begin{array}{l}\text { Less control } \\
\text { parameters, } \\
\text { Robustness, } \\
\text { performance. }\end{array}$ & $\begin{array}{l}\text { Efficient solutions for } \\
\text { multimodal and } \\
\text { multidimensional } \\
\text { optimization problems. }\end{array}$ \\
\hline $\begin{array}{l}\text { Modified fast } \\
\text { marriage in } \\
\text { honey bee } \\
\text { optimization } \\
\text { (MFMBO) } \\
\text { [25]. }\end{array}$ & $\begin{array}{l}\text { 1.Success rate and speed of MFMB is better than the } \\
\text { ABC,QB and FMBO with the tolerance of answer is } \\
\text { equal or less than } 10^{\wedge}-2 \text { and success rate as } 100 \% \text { of } \\
\text { all } \\
\text { 2. Improves the fitness of brood by using the selected } \\
\text { worker. }\end{array}$ & $\begin{array}{l}\text { Faster, robustness, } \\
\text { scalability, tolerance. }\end{array}$ & $\begin{array}{l}\text { Success rate, fitness, } \\
\text { speed. }\end{array}$ \\
\hline
\end{tabular}

Table-3.2: quality of service aware content distribution and different kinds of security implementation in p2p network

\begin{tabular}{|c|c|c|}
\hline Algorithm/method & Remarks & Advantages \\
\hline $\begin{array}{l}\text { peer authorization } \\
\text { protocol (PAP), } \\
\text { private key } \\
\text { generator (PKG), } \\
\text { NAT device, } \\
\text { digital rights } \\
\text { management } \\
\text { (DRM) techniques } \\
\text { [30]. }\end{array}$ & $\begin{array}{l}\text { 1. PAP-to differentiate illegal nodes. } \\
\text { 2. Identity-based signatures-IBS (authorization verification), } \\
\text { Gossip Trust System time stamped tokens -to identify pirated } \\
\text { copies through secure file indexes. } \\
\text { 3.10 PC-based distribution agents for a swarm size of } 2,000 \\
\text { peers. } \\
\text { 4. } 99.9 \text { percent of illegal prevention rate in Gnutella, KaZaA } \\
\text { and Freenet is achieved and } 85-98 \text { percent prevention rate on } \\
\text { eMule, eDonkey, Morpheus. }\end{array}$ & $\begin{array}{l}\text { System performance, minimum } \\
\text { delivery cost, higher content } \\
\text { availability less overhead. }\end{array}$ \\
\hline $\begin{array}{l}\text { Trusted Computing } \\
\text { Group (TCG), } \\
\text { DAA (direct } \\
\text { anonymous } \\
\text { attestation)- sign\& } \\
\text { verify algorithm, } \\
\text { Trusted Platform } \\
\text { Module(TPM)[22]. }\end{array}$ & $\begin{array}{l}\text { 1. TPM-integrity, privacy. } \\
\text { 2. Pseudonymous authentication mechanism-peers can } \\
\text { authenticate other peers. } \\
\text { 3. Authenticated key exchanges- integrated with the SSL/TLS } \\
\text { and IPSec protocol. }\end{array}$ & $\begin{array}{l}\text { Access control, accountability, } \\
\text { confidentiality and integrity. }\end{array}$ \\
\hline
\end{tabular}




\begin{tabular}{|c|c|c|}
\hline $\begin{array}{l}\text { Origin server (OS), } \\
\text { Trust Index Table } \\
\text { (TIT)[7]. }\end{array}$ & $\begin{array}{l}\text { 1. Trust value calculation-On success of data delivery ratio } \\
\text { \&search time for trusted nodes. } \\
\text { 2. Query sending rate-from } 250 \mathrm{~Kb} \text { to } 1 \mathrm{Mb} \text { increases when trust } \\
\text { evaluation is applied. } \\
\text { 3. Delay is decreases at trust evaluation and drop is constant in } \\
\text { the trust based case. }\end{array}$ & $\begin{array}{l}\text { Increased success ratio with reduced } \\
\text { delay and drop. }\end{array}$ \\
\hline $\begin{array}{l}\text { Signature scheme, } \\
\text { random linear } \\
\text { coding based } \\
\text { content distribution } \\
\text { [11]. }\end{array}$ & $\begin{array}{l}\text { 1. Random linear coded Scheme-secure distribution with } \\
\text { negligible overhead for large files. } \\
\text { 2. For } 10 \mathrm{MB} \text { file the overhead is less than } \\
0.1 \% \text { of the file size. }\end{array}$ & $\begin{array}{l}\text { Integrity, less overhead for large } \\
\text { files, increased efficiency, improved } \\
\text { robustness and reduced } \\
\text { downloading time. }\end{array}$ \\
\hline $\begin{array}{l}\text { Poisoning resistant } \\
\text { security framework } \\
{[19] .}\end{array}$ & $\begin{array}{l}\text { 1.Poisoning-resistant security framework- effectively and } \\
\text { efficiently defend against } \\
\text { content poisoning through man-in-the-middle (MITM), Sybil } \\
\text { and DoS attacks. } \\
\text { 2. DHT-to content availability\& scalability. } \\
\text { 3. Scalable probabilistic verification scheme-to reduce } \\
\text { verification overhead. }\end{array}$ & $\begin{array}{l}\text { Integrity, availability } \\
\text { and scalability. }\end{array}$ \\
\hline $\begin{array}{l}\text { Content authentic- } \\
\text { cation protocol, } \\
\text { rational content } \\
\text { access sub protocol } \\
\text { secure content } \\
\text { distribution } \\
\text { protocol [9]. }\end{array}$ & $\begin{array}{l}\text { 1. Byzantine agreement -authentication and cryptographic } \\
\text { puzzles. } \\
\text { 2. Signature generation sub protocol (SGS)-authenticity and } \\
\text { integrity. } \\
\text { 3. Signature verification sub protocol (SVS)-trust is on Trust } \\
\text { Management System(TMS). }\end{array}$ & $\begin{array}{l}\text { Integrity, reliability, secure and } \\
\text { authentication. }\end{array}$ \\
\hline $\begin{array}{l}\text { Integrated system } \\
\text { solution for secure } \\
\text { P2P content } \\
\text { distribution based } \\
\text { on Network } \\
\text { Coding(ISNC)[14]. }\end{array}$ & $\begin{array}{l}\text { 1. Network coding-improve resilience to peer churn \& shorter } \\
\text { the downloading time. } \\
\text { 2. Secure network coding signature scheme- group network } \\
\text { coding authentication. } \\
\text { 3. An identity-based malicious peer identification scheme- } \\
\text { Bottom-up \& Top-down approach to identify malicious peer. }\end{array}$ & $\begin{array}{l}\text { High throughput, high security, high } \\
\text { reliability, reduced computation } \\
\text { overhead and improved overall } \\
\text { efficiency. }\end{array}$ \\
\hline $\begin{array}{l}\text { Identity-based } \\
\text { encryption, Private } \\
\text { Key Generator } \\
\text { (PKG), asymmetric } \\
\text { key algorithms } \\
{[26] .}\end{array}$ & $\begin{array}{l}\text { 1. IBE-Useful where pre-distribution of authenticated keys is } \\
\text { inconvenient and eliminates the need for a public key } \\
\text { distribution infrastructure. } \\
\text { 2. PKG- private key to decrypt or sign messages. } \\
\text { 3. RSA algorithm for safer data replication. }\end{array}$ & $\begin{array}{l}\text { Secure Authenticity, integrity, } \\
\text { confidentiality, reduces overheads, } \\
\text { prevent Sybil attacks, query } \\
\text { efficiency, high replica hit rate. }\end{array}$ \\
\hline $\begin{array}{l}\text { Security } \\
\text { certificates, X.509, } \\
\text { ASN, DER, } \\
\text { Certification } \\
\text { Authority (CA), } \\
\text { firewall, PKI, } \\
\text { EJBCA(Enterprise } \\
\text { Java Bean Certifi } \\
\text { cate Authority) } \\
\text { associated with } \\
\text { OpenSSL[32]. }\end{array}$ & $\begin{array}{l}\text { 1. ASN.1 distinguished encoding rules (DER) [X.690]-data } \\
\text { encoding. } \\
\text { 2. Firewall supports FTP file filter-attachments of DOC and } \\
\text { ZIP files in E-mails to find } \\
\text { dangerous information to reduce the DOS } \\
\text { (Denial of Service) attacks. } \\
\text { 3. Attribute certificate-specify group membership, role, security } \\
\text { clearance, other authorization information. }\end{array}$ & $\begin{array}{l}\text { Access control, secure } \\
\text { transmissions, fault tolerance, } \\
\text { accuracy, lower cost, improved } \\
\text { security. }\end{array}$ \\
\hline
\end{tabular}




\begin{tabular}{|c|c|c|}
\hline $\begin{array}{l}\text { Intrusion detection } \\
\text { systems, distributed } \\
\text { security policy, } \\
\text { FIPA specification } \\
\text { learning algorithms } \\
\text { [27]. }\end{array}$ & $\begin{array}{l}\text { 1. JXTA, WiFi OBEX -P2P communication. } \\
\text { 2. Contact list -contains the list of neighbor nodes of P2P } \\
\text { provider. } \\
\text { 3.Learning algorithms-optimal configuration, improve } \\
\text { performance. }\end{array}$ & $\begin{array}{l}\text { Scalability, autonomy, monitor } \\
\text { heterogeneous processes and } \\
\text { devices, expandability, fault } \\
\text { tolerant, less overhead for } \\
\text { communication, efficiency, } \\
\text { reliability. }\end{array}$ \\
\hline $\begin{array}{l}\text { Ownership model, } \\
\text { security policy } \\
\text { definition } \\
\text { language(SPDL), } \\
\text { authentic key } \\
\text { exchange, Diffie- } \\
\text { Hellman key } \\
\text { exchange protocol } \\
\text { [8]. }\end{array}$ & $\begin{array}{l}\text { 1. Security policy of a device- same as the Resurrecting } \\
\text { Duckling Policy Model. } \\
\text { 2. Ownership model relations -redundancy to cope in situations } \\
\text { where devices get lost or delegated and builds p2p security } \\
\text { relations between devices that are trusted. } \\
\text { 3. Remote configuration -to support limited user interface \& } \\
\text { authentic key exchange to security relations. }\end{array}$ & $\begin{array}{l}\text { Access control, authority, } \\
\text { authentication, exception handling, } \\
\text { limited devices, privacy, self- } \\
\text { configuration in dynamic networks. }\end{array}$ \\
\hline $\begin{array}{l}\text { Symmetric encrypt } \\
\text {-tion, public key } \\
\text { encryption, tunnel, } \\
\text { signature } \\
\text { verification keys, } \\
\text { digital signature, } \\
\text { Search for } \\
\text { Extraterrestrial } \\
\text { Intelligence (SETI) } \\
\text { [1]. }\end{array}$ & $\begin{array}{l}\text { 1. Gossip model-initial node discovery and subsequent network } \\
\text { maintenance. } \\
\text { 2. SETI - accountability mechanism to replicate all } \\
\text { computation to quality control. } \\
\text { 3. Network Address Translator- sends packet to final } \\
\text { destination through internet. } \\
\text { 4. Public key encryption.-secure content. } \\
5 \text { Groove's decentralization improves robustness. }\end{array}$ & $\begin{array}{l}\text { Fault tolerant, reliable, survivability, } \\
\text { highly scalable, flexibility, expected } \\
\text { latency, robustness, authenticity, } \\
\text { confidentiality and integrity of } \\
\text { messages, high robust anonymity } \\
\text { and document durability. }\end{array}$ \\
\hline $\begin{array}{l}\text { Digital signature, } \\
\text { security-update } \\
\text { propagation } \\
\text { software } \\
\text { [34]. }\end{array}$ & $\begin{array}{l}\text { 1. Upgrades-To detect a flaw in the code and to enhance } \\
\text { performance or extend the functionality. } \\
\text { 2. Digital signature (encrypted by private key)-verify the } \\
\text { originality. }\end{array}$ & $\begin{array}{l}\text { Enhanced performance, extended } \\
\text { functionality, faster requests } \\
\text { \&responses, save time of download } \\
\text { and install, support of multiple } \\
\text { platforms, self immune to malicious } \\
\text { nodes. }\end{array}$ \\
\hline
\end{tabular}

\section{FUTURE WORK}

In order to improve the QoS and security advanced P2PHBA algorithm can be used with scout bee implementation for the prediction of optimized path to efficient file sharing, better sources to selective retrieval, time efficient, robust sharing mechanism, lower control overhead, higher success ratio amidst changing mobility and high node density. The efficient content distribution with secured network are identified by trust management techniques to recognize trustworthy peers on P2P network to collect the peers trust values, authorization protocol , private key generator. Implementation of key server/origin server with IDS may improve the security of the network without affecting the performance of content distribution over the peers. Implementation of key server is to provide session keys to all nodes in the network at the configuration period for the first layer of security. At the time of routing Intrusion Detection System (IDS) is initiated for monitoring the nodes which also act as a cluster to achieve second wall of defence against intruder in the operation. TA (Trust Authority) is used to make the identification of malicious nodes in all over the network. For the dynamic routing purpose nodes outside the network coverage need to get authenticated by IDS. Here IDS not only monitor the malicious activities it also remove or prevent those unwanted activities. So IDS is simply called as intrusion detection and prevention system (IDPS) which is primarily focused on identifying possible incidents, logging those information, reporting those attempts, identifying problems with security policies, document the existing threats and avoiding the individuals from violating security policies. While compare to other security mechanisms the implementation of IDPS will consume reasonable energy will not affect the battery life Monitoring allows one to detect, analyze and recover from detected faults and also provides additional defense against catastrophic failures. By using these double layer security and Swarm Intelligence methodologies QoS is achieved with better security

\section{CONCLUSIONS}

This paper conducts a theoretical analysis study on secured and QoS based content distribution in distributed computing system (peer-to-peer network). Because of the usage of a population of solutions for every iteration instead of a single solution SI algorithms can improve the performance of file 
sharing network. A brief discussion of different content distribution techniques and different security implementations are summarized. Also the advantages of efficient content distribution is summarized with suggestions are given for the efficient content distribution in a secured manner.

\section{REFERENCES}

[1]. Allan Friedman; Jean, L.( 2003): "Peer-to-Peer Security" Telecommunications Policy Research Conference, Washington DC, September.

[2]. Anandaraj, M.; Ganeshkumar, P. ;Vijayakumar K.P.( 2013):" An Efficient QOS Based Multimedia Content Distribution Mechanism in P2P Network “ ISSN: 2277 128X ,International Journal of Advanced Research in Computer Science and Software Engineering, May.

[3]. Anna Saro Vijendran; Thavamani, S.(2013):“An Efficient Algorithm For Clustering Nodes Classifying And Replication Of Content On Demand Basis For Content Distribution In P2P Overlay Networks" International Journal of Computer \& Communication Technology ISSN (PRINT): 0975 - 7449.

[4]. Anusuya, R.; Kavitha,V,;Mrs Golden Julie, E. (2010):"Enhancing and Analyzing Search performance in Unstructured Peer to Peer Networks Using Enhanced Guided Search Protocol (EGSP)" , ISSN 2151-9617 Journal of Computing, Volume 2, Issue 6, June.

[5]. Ayyasamy, S.; Sivanandam, S.N.(2010):“A Cluster Based Replication Architecture for Load Balancing in Peer-to-Peer Content Distribution" International Journal of Computer Networks \& Communications (IJCNC)September.

[6]. Ayyasamy, S.; Sivanandam, S.N.(2009): ”A QoS Aware Intelligent Replica Management Architecture for Content Distribution in P2P Overlay Networks" ISSN : 0975-3397 International Journal on Computer Science and Engineering . [7]. Ayyasamy, S; Sivanandam, S.N.(2010): "Trust Based Content Distribution for Peer-To-Peer Overlay Networks" International Journal of Network Security \& Its Applications (IJNSA), Volume 2, Number 2, April.

[8]. Christian Rohner.(2006): "Security Bootstrapping for Networked Devices" European Workshop on Security in Adhoc and Sensor Networks - ESAS , pp. 165-178, 2006.

[9]. Esther Palomar Juan, M.; Estevez Tapiador Julio, C.; Hernandez-Castro; Arturo Ribagorda.(2006): "A Protocol for Secure Content Distribution in Pure P2P Networks", DEXA Workshops 2006: 712-716. Proceeding 06 Proceedings of the 17th International Conference on Database and Expert Systems Applications ISBN:0-7695-2641-1.

[10]. Evariste Logota, Hugo Marques, Jonathan Rodriguez Fernando Pascual, Manuel Nuñez, Ignacio Digón (2013)“A A Scalable Approach for QoS Control in P2P Networking” ictromeo.eu,Sep 28.

[11]. Fang Zhao; Ton Kalker; Muriel Medard and Keesook, J.; Han.(2007): "Signatures for Content Distribution with Network Coding", In Proc. of International Symposium on Information Theory (ISIT).
[12]. Haribabu, K.; Dayakar Reddy; Chittaranjan Hota Antii Ylä-Jääski; Sasu Tarkoma. (2012):“Adaptive Lookup for Unstructured Peer-to-Peer Overlays” IEEE Arrangement Graph-Based Overlay with Replica Mechanism File Sharing, Pervasive Systems, Algorithms and Networks (ISPAN), 12th International Symposium.

[13]. Heba, A.; Kurida Thanaa, S.; Alnusairib; Hajar S.; Almujaheda Heba, A.; Kurid.(2013):“OBAME: Optimized Bio-inspired Algorithm to Maximize Search Efficiency in P2P Databases" The 4th International Conference on Emerging Ubiquitous Systems and Pervasive Networks (EUSPN).

[14]. Heng He; Ruixuan Li; Guoqiang Gao; Zhiyong Xu; Weijun Xiao.(2011): “An Integrated System Solution for Secure P2P Content Distribution Based on Network Coding" Proceedings of NAS '11 Proceedings of the 2011 IEEE Sixth International Conference on Networking, Architecture, and Storage, 28-30 July 2011, 191-196, ISBN: 978-0-7695-45097.

[15]. Jing Zhao; Ping Zhang and Guohong Cao (2013):“'On Cooperative Caching in Wireless P2P Networks " National Science Foundation (NSF) under grant CNS-0721479, Aug 24.

[16]. Laurent Eschenauer; John, S.; Baras Virgil Gligor.(2003):"Distributed Trust Establishment in MANET's: Swarm Intelligence".

[17]. Malcolm Yoke Hean Low; Mahinthan Chandramohan; Chwee Seng Choo.(2009): "Application Of Multi-Objective Bee Colony Optimization Algorithm To Automated Red Teaming" 978-1-4244-5771-7/09/2009 IEEE.

[18]. Nguyen Quynh Anh; Nguyen Tung Linh (2010):“Application artificial bee colony algorithm (ABC) for reconfiguring distribution network" 2010 Second International Conference on Computer Modeling and Simulation (ICCMS)978-0-7695-3941-6/10/2011, IEEE.

[19]. Ruichuan Chen; Eng Keong Lua; Jon Crowcroft; Wenjia Guo; Liyong Tang; Zhong Chen.(2008): "Securing Peer-toPeer Content Sharing Service from Poisoning Attacks" pp. 2229 , 8th International Conference in $p 2 p$ computing, IEEE, 2008.

[20]. Sabu, M.; Thampi; Chandra Sekaran, K.(2010 ):"Protocols for Bio-Inspired Resource Discovery and Erasure Coded Replication in P2P Networks“ INFOCOMP Journal of Computer Science, ISSN 1807-4545, June.

[21]. Sanjay; Dhurandher, K.; Sudip Misra; Shubham Singhal; Saurabh Aggarwal; Puneet Pruthi; Isaac Woungang.(2009):" A Swarm Intelligence-Based P2P File Sharing Protocol Using Bee Algorithm" IEEE.

[22]. Shane Balfe; Amit, D.; Lakhani and Kenneth, G.; Paterson.(2005):“Trusted Computing: Providing Security for Peer-to-Peer Networks", Fifth IEEE International Conference on Peer-to-Peer Computing (P2P 2005), 31 August - 2 September 2005, Konstanz, Germany. IEEE Computer Society 2005 ISBN 0-7695-2376-5, Stamp Collectors Against Dodgy Sellers (SCADS) institute, 117-124.

[23]. Syed Raziuddin; Syed Abdul Sattar; Rajya Lakshmi and Moin Parvez (2011): "Differential Artificial Bee 
Colony for Dynamic Environment" CCSIT 2011, SpringerVerlag Berlin Heidelberg.

[24]. Tsungnan Lin; Senior Member; Pochiang Lin; Hsinping Wang and Chiahung Chen.(2009):"Dynamic Search Algorithm in Unstructured Peer-to-Peer Networks" IEEE Transactions On Parallel And Distributed Systems, MAY.

[25]. Vakil-Baghmisheh, M.; Mina Salim, T.(2010):”A Modified Fast Marriage in Honey Bee Optimization Algorithm"978-1-4244-8185-9/10/2010 5th International Symposium on Telecommunications (IST'2010),IEEE.

[26]. Vijaya Bharath, K.; Praveen Kumar, B.; Rajagopalan, S.P.(2012):"An Identity-Based Security for Nodes in EAD File Replication in P2P Systems" ISSN: 2278-5183 International Journal of Computers and Distributed Systems www.ijcdsonline.com Vol. No.1, Issue 3, October 201288.

[27]. Vladimir Gorodetsky; Oleg Karsaev; Vladimir Samoylov; Sergey Serebryakov (2007):"Multi-agent Peer-toPeer Intrusion Detection" ,260-271, Fourth International Conference on Mathematical Methods, Models, and Architectures for Computer Network Security, MMM-ACNS 2007 St. Petersburg, Russia, September 13-15, 2007 Proceedings, I SBN 978-3-540-73985-2.

[28]. Wenping Zou; Yunlong Zhu; Hanning Chen; Hai Shen (2011):“A Novel Multi-Objective Optimization Algorithm Based on Artificial Bee Colony" GECCO'11, ACM 978-14503-0690-4/11/07,July 12-16.

[29]. Xiaojun Bi Yanjiao Wang.(2011):“An Improved Artificial Bee Colony Algorithm" 978-1-61284-840-2/11/2011 IEEE.

[30]. Xiaosong Lou and Kai Hwang.(2009): "Collusive Piracy Prevention in P2P Content Delivery Networks" Published by the IEEE Computer Society, IEEE transactions on computers, VOL. 58, NO. 7, july 2009, 0018-9340/09/\$25.00, 2009 IEEE. [31]. Yuqing Zhou (2011):"On the Performance of P2P Network: An Assortment method" arXiv.org physics.data-an 1109.2611.

[32]. Yuting Liu; Xiaofeng Qiu; Yang Ji; Chunhong Zhang.(2011):" A Novel Security Mechanism to Defend Cross-layer Security Threats in P2P Network" 978-1-42447255-0/11/\$26.00 @2011 IEEE.

[33]. Yu-Wei Chen and Yu-Hao Huang.(2011): "An Interactive Streaming Service over Peer-to-Peer Networks" International Conference on Software and Computer Applications IPCSIT vol.9 IACSIT Press.

[34]. Zakiya, M.; Tamimi.(2007):“"Automated Peer-to-Peer Security-Update Propagation Network", Proceeding ICCOMP'07 Proceedings of the 11th WSEAS International Conference on Computers,, 557-564, ISBN: 978-960-845795-9 